\title{
SENYAWA STIGMASTEROL (STEROID) DARI KULIT BATANG Chisocheton celebicus koord (MELIACEAE)
}

\author{
Dewa Gede Katja \\ Program Studi Kimia, Fakultas Matematian dan Ilmu Pengetahuan Alam Universitas Sam Ratulangi, Manado \\ E-mail: dewakatja@unsrat.ac.id
}

\begin{abstract}
ABSRTAK
Stigmasterol (suatu steroid) dengan rumus molekul $\mathrm{C}_{29} \mathrm{H}_{48} \mathrm{O}$ telah doiisolasi dari kulit batang chisocheton celebicus (Meliacea) menggunakan pelarut $n$-heksan, kemudian dipisahkan dengan teknik kromatografi dan dihasilkan isolat murni berupa kristal jarum tak berwarna(10,2 mg) dengan titik leleh $169-171^{\circ} \mathrm{C}$. Struktur kimia stigmasterol diidentifikasi berdasarkan data-data spektroskopi meliputi IR, NMR-1D, NMR-2D dan masa,serta perbandingan dengan data spektroskopi yang diperoleh dari literatur. Penemuan senyawa stigmasterol dari kulit batang Chisocheton celebicus dilaporkan untuk pertama kalinya dalam penelitian ini..
\end{abstract}

Kata kunci: Meliaceae, Chisocheton celebicus koord, stigmasterol.

\begin{abstract}
Stigmasterol $\mathrm{C}_{29} \mathrm{H}_{48} \mathrm{O}$ has been isolated from the bark of Chisocheton celebicus (Meliacee) in $n$-hexan and separated using several chromatography and it has been pure isolated the crystal calorness compound $(10,2$ $\mathrm{mg}$ ). The chemical structure of isolated compound was identified on the basis of spectroscopic data including IR, 1D-NMR, 2D-NMR and mass along with comparison with those spectral data previously reported. The discovery of stigmasterol compound from the bark C. celebicus reported for the first time in this study.
\end{abstract}

Keyword: Meliaceae, Chisocheton celebicus koord, stigmasterol

\section{PENDAHULUAN}

Tumbuhan Chisocheton celebicus adalah salah satu spesies dari genus Chisocheton yang terdistribusi secara luas di daerah tropis dan subtropis seperti Nepal, India, Bhutan, Myanmar, Indo-China, Thailand, Malaysia dan Papua Nugini (Vosen \& Umali, 2002). Chisocheton pada umumnya sering ditemukan di dataran rendah hutan hujan tropis dan beberapa spesies tumbuhan ini secara tradisional telah digunakan sebagai obat pencuci perut, berbau khas (tengik) dan susah untuk dikeringkan serta dimanfaatkan sebagai racun untuk penangkapan ikan (Lim, 2008).

Berdasarkan jurnal dari genus tumbuhan ini, telah dilaporkan dan menghasilkan senyawa aktif yang bersifat antikanker, sitotoksik, antitumor, antiinflamasi, antimalaria, antimikroba, antilipid dan apoptosisi (Wong dkk.,2011; Mohamad dkk., 2008; Yang dkk.,
2009; Awang dkk., 2012; Najmuldeen dkk., 2012). Senyawa aktif yang diisolasi dari genus Chsocheton adalah ceramicin A, merupakan golongan limonoid baru yang diisolasi dari kulit batang $C$. ceramicus, beraktivitas sitotoksik terhadap sel murin leukemia P-388 (Mohammad dkk., 2008). Senyawa triterpenoid yang diisolasi dari daun $C$. macrophyllus memiliki sifat antitumor terhadap sel tumor pada EBV-EA (Inada dkk., 1993). Ceramicin B merupakan senyawa limonoid yang diisolasi dari kulit batang $C$. ceramicus memeliki aktivitas antilipid (Wong dkk., 2013). Senyawa malayanin A dan malayanin B, merupakan senyawa limonoid yang diisolasi dari kulit batang C. erytrocarpus Hiern, beraktivitas antimalaria dan insektisida (Awang dkk., 2012). Senyawa 7 $\alpha$-hidroksi- $\beta$ sitosterol, diisolasi dari kulit batang $C$. tomentosus yang beraktivitas apoptosis (Najmuldeen dkk., 2012). Dalam penelitian ini kami akan mengisolasi dan identifikasi struktur 
senyawa stigmasterol (suatu steroid) dengan rumus molekul $\mathrm{C}_{29} \mathrm{H}_{48} \mathrm{O}$.

\section{BAHAN DAN METODE}

Kulit batang tumbuhan C. celebicus diperoleh dari Kebun Raya Bogor Jawa Barat. Tumbuhan ini dideterminasi di Herbarium Bogoriense Bogor Jawa Barat dan contoh specimen ini tersimpan di Herbarium tersebut. Bahan-bahan yang digunakan adalah silika gel $\mathrm{G}_{60}$ (70-230 mesh dan 200-400 mesh, Merck), silika gel $\mathrm{GF}_{254}$ (Merck, 0,25 mm) untuk kromatografi lapis tipis, asam sulfat dan etanol diperoleh dari Merck (Damstadt, Germany)

\section{Ekstraksi dan isolasi}

Kulit batang tumbuhan C. celebicus (2
$\mathrm{kg}) \quad$ kering dilahaluskan, diekstraksi mengunakan metode maserasi (ekstrak padatcair) dengan pelarut $n$-heksana, etil asetat dan metanol pada suhu ruangan. Fraksi $n$-heksana dipekatkan dengan rotary evaporator sehingga diperoleh ekstrak pekat $n$-heksana $(26,8 \mathrm{~g})$. Selnjutnya dipisahkan dengan metode kromatografi cair vakum (KCV) menggunakan fasa diam silika gel $\mathrm{G}_{60}$ dan fasa gerak campuran pelarut $n$-heksana, etil asetat dan metanol yang dielusikan bertahap secara bergradien $10 \%$ sehingga diperoleh 3 fraksi (A-C). Fraksi B $(0,15 \mathrm{~g})$ dipisahkan dengan kromatografi kolom pada silika gel (70-230 mesh) dengan sistem pelarut $n$-heksana-etil asetat bergradien (10:08:2), dihasilkan sembilan fraksi (B1-B9). Fraksi B3 (42,7 mg) dipisahkan dengan teknik kromatografi kolom dengan fase diam silika gel $\mathrm{G}_{60}$ (230-400 mesh) dan fase geraknya berupa perbandingan pelarut tetap $n$-heksana : aseton
(9,5:0,5) dihasilkan sepuluh fraksi (B3.1-10). Berdasarkan hasil analisis kromatograpi lapis tipis fraksi (B3.5-8) digabungkan dan dihasilkan isolat murni berbentuk padatan kekuningan, selanjutnya direksistalisasi dengan metanol diperoleh senyawa stigmasterol berbentuk kristal tak berwarna sebanyak 10,2 mg., Setiap tahapan pemisahan dipantau dengan kromatografi lapis tipis dibawah sinar UV ( $\lambda 254 \mathrm{~nm}$ dan $\lambda 365$ $\mathrm{nm})$. Isolat murni tersebut diidentifiksi strukturnya berdsarakan data-data spektroskopi IR (FTIR One Perkin Elmer pada KBr), ${ }^{1} \mathrm{H}-$ NMR dan ${ }^{13} \mathrm{C}$-NMR (spektrometer JEOL JNM ECA-500).

\section{HASIL DAN PEMBAHASAN}

Spektrum IR ( $\mathrm{KBr}$ ) senyawa (Gambar 1) menunjukkan kehadiran gugus hidroksil (3401 $\left.\mathrm{cm}^{-1}\right), \mathrm{C}-\mathrm{H} s p^{3}\left(2937 \mathrm{~cm}^{-1}\right)$, gugus olefinik $\mathrm{C}=\mathrm{C}$ $s p^{2}\left(1457 \mathrm{~cm}^{-1}\right)$ dan gugus $\mathrm{C}-\mathrm{O}\left(1052 \mathrm{~cm}^{-1}\right)$. Spektrum ${ }^{1}$ H-NMR senyawa (Gambar 2) menunjukkan kehadiran enam sinyal metil $s p^{3}$ yang terdiri atas dua sinyal metil tersier yang beresonansi pada $\delta_{\mathrm{H}} 0,67(3 \mathrm{H}, \mathrm{s})$ dan $1,00(3 \mathrm{H}$, s), tiga metil sekunder pada $\delta_{\mathrm{H}} 0,92(3 \mathrm{H}, \mathrm{d}, J=$ $6,5 \mathrm{~Hz}), 0,84(3 \mathrm{H}, \mathrm{d}, J=6,4 \mathrm{~Hz})$, dan $0,82(3 \mathrm{H}$, d, $J=6,1 \mathrm{~Hz}$ ), serta satu sinyal metil primer yang beresonansi pada $\delta_{\mathrm{H}} 0,80(3 \mathrm{H}, \mathrm{t}, J=6,0$ $\mathrm{Hz})$ yang menyarankan karakteristik senyawa golongan steroid (Yayli \& Baltaci, 1996). Kehadiran tiga sinyal metin olefinik beresonansi pada $\delta_{\mathrm{H}} 5,35(1 \mathrm{H}, \mathrm{d}, J=5,2 \mathrm{~Hz}, \mathrm{H}-6), 5,16(1 \mathrm{H}$, dd, $J=8,5 ; 15,0 \mathrm{~Hz}, \mathrm{H}-22)$, dan $5,00(1 \mathrm{H}$, dd, $J$ $=8,5 ; 15,0 \mathrm{~Hz}, \mathrm{H}-23)$, serta satu sinyal metin teroksigenasi pada $\delta_{\mathrm{H}} 3,52(1 \mathrm{H}, \mathrm{q}, J=16,5 \mathrm{~Hz}$, H-3) menyarankan karakteristik senyawa 3- $\beta$ stigmasterol (Cayme \& Ragasa, 2004; Yayli \& Baltaci, 1996). 


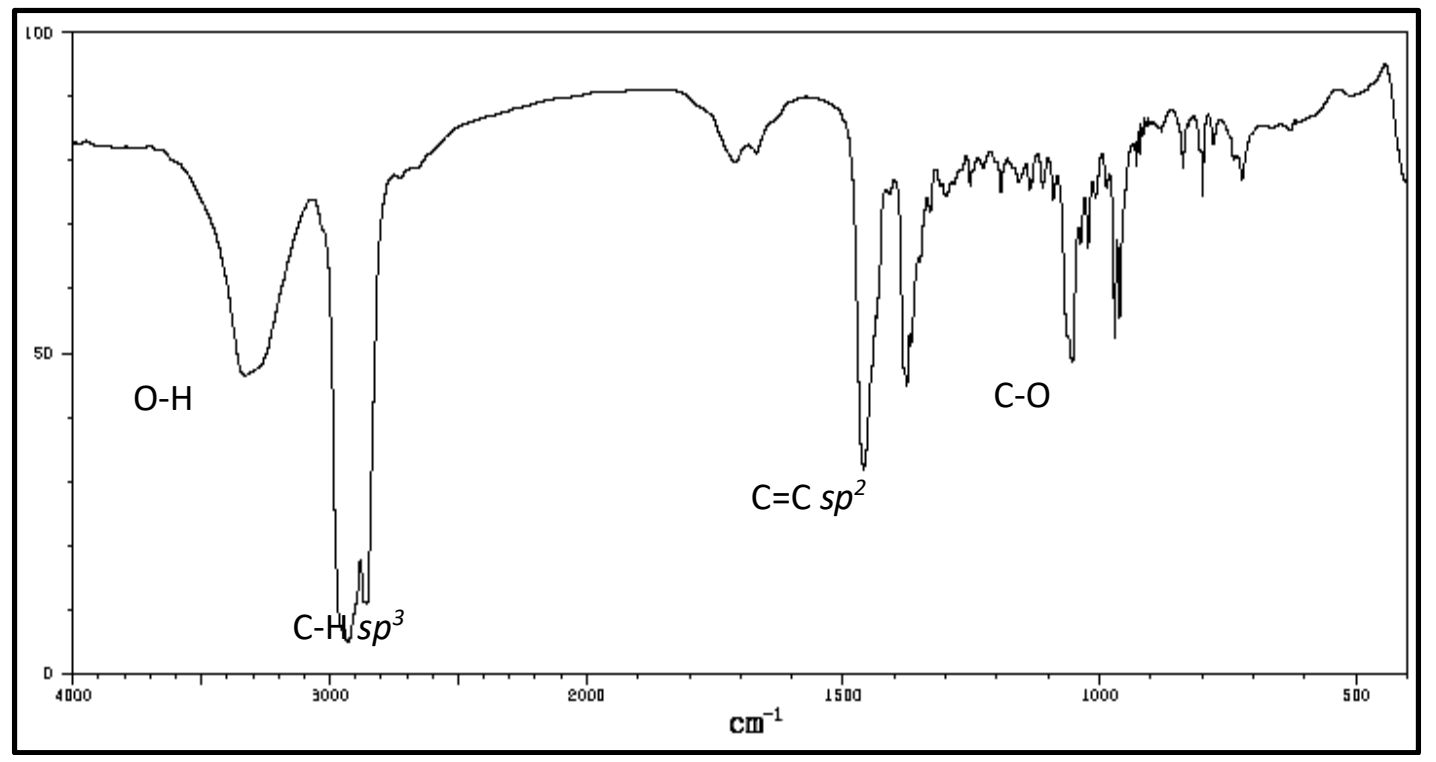

Gambar 1. Spektrum inframerah senyawa 1

Spektrum ${ }^{13} \mathrm{C}$-NMR senyawa (Gambar 3) diperinci dengan percobaan DEPT $135^{\circ}$ menunjukkan adanya 29 sinyal karbon yang terdiri atas enam metil, sepuluh metilen, sebelas metin dan dua sinyal karbon kuarterner yang menyarankan senyawa golongan steroid (Yayli \& Baltaci, 1996). Kehadiran enam sinyal metil yang beresonansi pada $\delta \mathrm{c} 12,1(\mathrm{C}-18)$ 19,5 (C19), 21,2 (C-21), 21,3 (C-26), 19,1 (C-27), dan 12,2 (C-29), satu sinyal oksimetin pada $\delta \mathrm{c} 72,0$
(C-3), tiga metin olefinik pada $\delta c 121,9$ (C-6), 138,5 (C-22), 129,5 (C-23) serta satu sinyal karbon olefinik singlet pada $\delta c$ 140,9 (C-5) menyarankan karakteristik senyawa stigmasterol (Cayme \& Ragasa, 2004; Yayli \& Baltaci, 1996). Fungsionalitas tersebut dihitung sebagai dua dari total enam derajat ketidakjenuhan. Empat derajat ketidakjenuhan yang tersisa, sesuai dengan kerangka dasar steroid stigmastan (Cayme \& Ragasa, 2004).

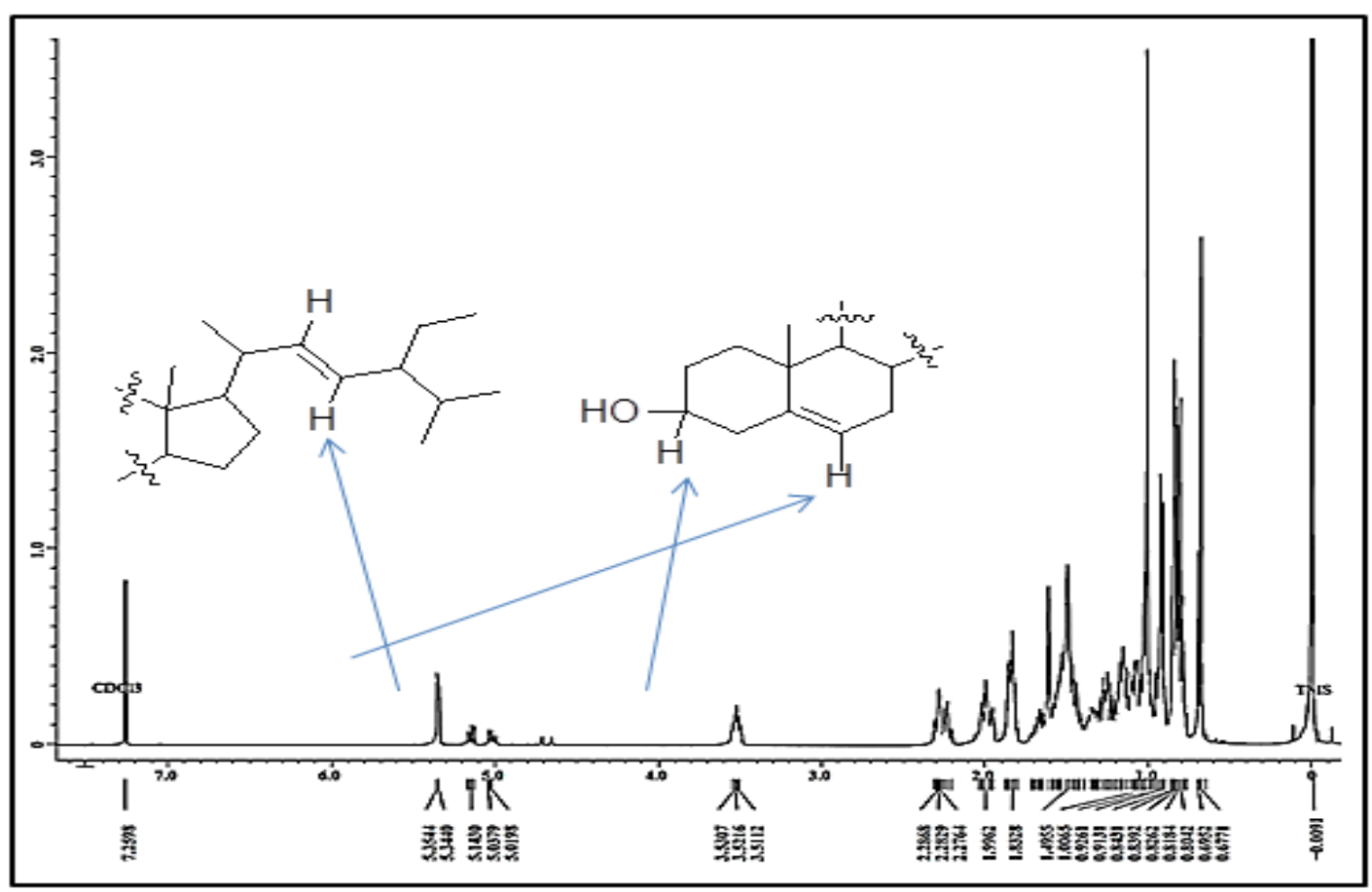

Gambar 2 Spektrum ${ }^{1} \mathrm{H}-\mathrm{NMR}$ senyawa $\left(\mathrm{CDCl}_{3}, 500 \mathrm{MHz}\right)$ 


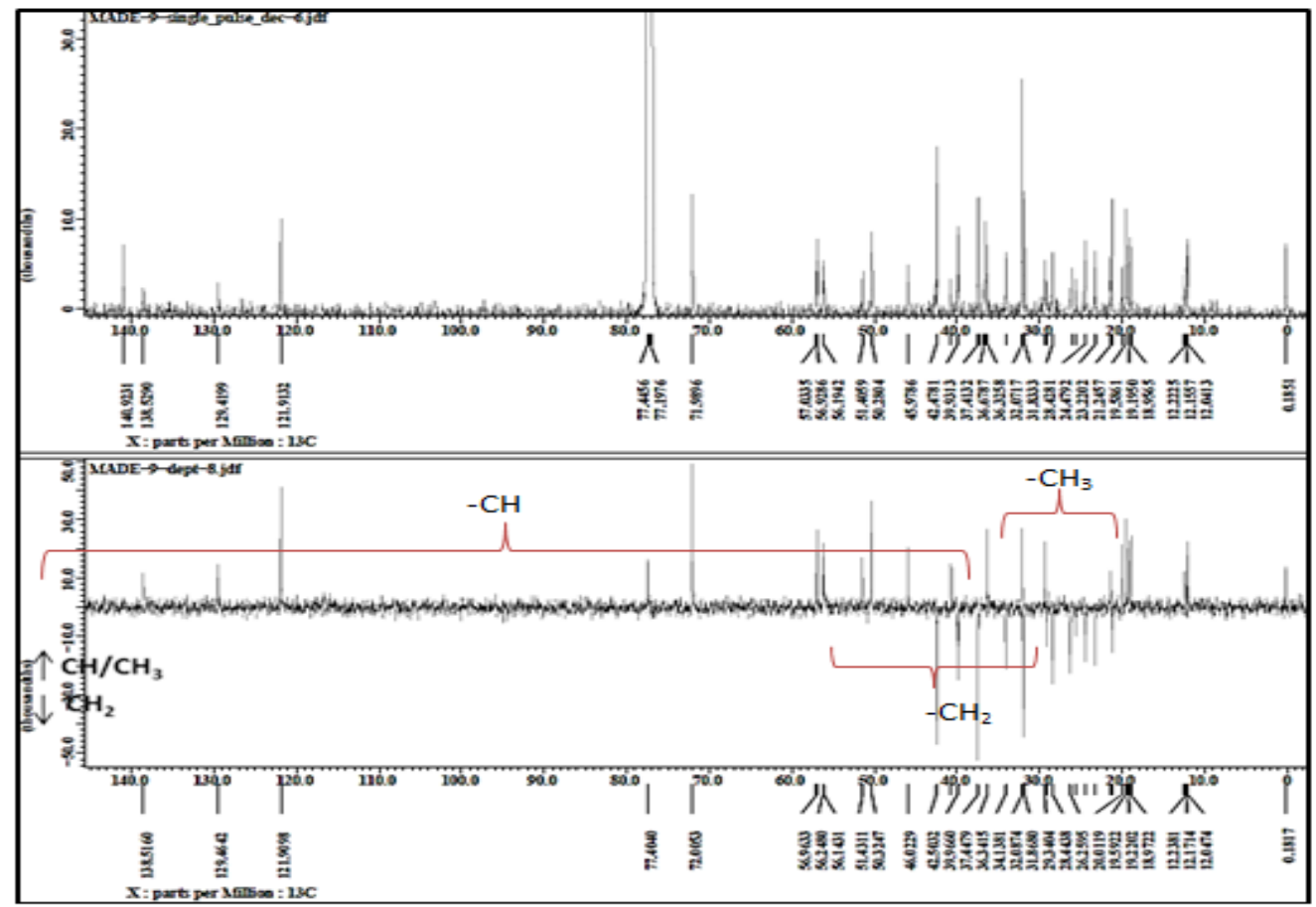

Gambar 3 Spektra ${ }^{13} \mathrm{C}-\mathrm{NMR}$ dan DEPT $135^{\circ}$ senyawa $\left(\mathrm{CDCl}_{3}, 125 \mathrm{MHz}\right)$

Perbandingan data spektroskopi senyawa dengan senyawa stigmasterol (Cayme \& Ragasa, 2004), menunjukkan bahwa kedua senyawa memiliki tingkat kesesuaian yang sangat tinggi, dengan demikian senyawa diidentifikasi sebagai stigmasterol (Gambar 4). 
Tabel. 1 Perbandingan data NMR senyawa dengan senyawa stigmasterol (Cayme \& Ragasa, 2004)

\begin{tabular}{|c|c|c|c|c|}
\hline \multirow{3}{*}{ Posisi } & \multicolumn{2}{|r|}{ Senyawa } & \multicolumn{2}{|r|}{ Stigmasterol* } \\
\hline & ${ }^{13} \mathrm{C}$ NMR & ${ }^{1} \mathrm{H}$ NMR & ${ }^{13} \mathrm{C}$ NMR & ${ }^{1} \mathrm{H}$ NMR \\
\hline & $\delta \mathrm{c}$ (mult) & $\delta_{\mathrm{H}}($ Integral, mult, $J=\mathrm{Hz})$ & $\delta \mathrm{c}$ (mult) & $\delta_{\mathrm{H}}($ Integral, mult, $J=\mathrm{Hz})$ \\
\hline \multirow[t]{2}{*}{1} & $37,4(\mathrm{t})$ & $1,08(1 \mathrm{H}, \mathrm{m})$ & $37,2(\mathrm{t})$ & $1,08(1 \mathrm{H}, \mathrm{m})$ \\
\hline & & $1,84(1 \mathrm{H}, \mathrm{m})$ & & $1,83(1 \mathrm{H}, \mathrm{m})$ \\
\hline \multirow[t]{2}{*}{2} & $31,8(\mathrm{t})$ & $1,49(1 \mathrm{H}, \mathrm{m})$ & $31,6(t)$ & $1,49(1 \mathrm{H}, \mathrm{m})$ \\
\hline & & $1,81(1 \mathrm{H}, \mathrm{m})$ & & $1,82(1 \mathrm{H}, \mathrm{m})$ \\
\hline 3 & 72,0 (d) & $3,52(1 \mathrm{H}, \mathrm{m})$ & $71,8(d)$ & $3,53(1 \mathrm{H}, \mathrm{m})$ \\
\hline \multirow[t]{2}{*}{4} & $42,5(\mathrm{t})$ & $2,28(1 \mathrm{H}, \mathrm{dd}, 2,0 ; 5,2)$ & $42,3(t)$ & $2,24(1 \mathrm{H}, \mathrm{dd}, 1,9 ; 4,7)$ \\
\hline & & $2,30(1 \mathrm{H}, \mathrm{dd}, 2,0 ; 5,2)$ & & $2,28(1 \mathrm{H}, \mathrm{dd}, 1,9 ; 4,7)$ \\
\hline 5 & $140,9(\mathrm{~s})$ & - & $140,7(\mathrm{~s})$ & - \\
\hline 6 & $121,9(d)$ & $5,35(1 \mathrm{H}, \mathrm{d}, 5,2)$ & $121,7(d)$ & $5,35(1 \mathrm{H}, \mathrm{d}, 4,7)$ \\
\hline \multirow[t]{2}{*}{7} & $32,1(\mathrm{t})$ & $1,54(1 \mathrm{H}, \mathrm{m})$ & $31,9(\mathrm{t})$ & $1,53(1 \mathrm{H}, \mathrm{m})$ \\
\hline & & $1,96(1 \mathrm{H}, \mathrm{m})$ & & $1,98(1 \mathrm{H}, \mathrm{m})$ \\
\hline 8 & $32,0(\mathrm{~d})$ & $1,46(1 \mathrm{H}, \mathrm{m})$ & 31,9 (d) & $1,46(1 \mathrm{H}, \mathrm{m})$ \\
\hline 9 & $50,3(d)$ & $0,94(1 \mathrm{H}, \mathrm{m})$ & $50,1(d)$ & $0,94(1 \mathrm{H}, \mathrm{m})$ \\
\hline 10 & $36,7(\mathrm{~s})$ & - & $36,5(\mathrm{~s})$ & - \\
\hline \multirow[t]{2}{*}{11} & $21,3(\mathrm{t})$ & $1,46(1 \mathrm{H}, \mathrm{m})$ & $21,6(t)$ & $1,45(1 \mathrm{H}, \mathrm{m})$ \\
\hline & & $1,49(1 \mathrm{H}, \mathrm{m})$ & & $1,48(1 \mathrm{H}, \mathrm{m})$ \\
\hline \multirow[t]{2}{*}{12} & $39,9(\mathrm{t})$ & $1,15(1 \mathrm{H}, \mathrm{m})$ & $39,7(\mathrm{t})$ & $1,15(1 \mathrm{H}, \mathrm{m})$ \\
\hline & & $1,95(1 \mathrm{H}, \mathrm{m})$ & & $1,97(1 \mathrm{H}, \mathrm{m})$ \\
\hline 13 & $42,5(\mathrm{~s})$ & - & $42,2(\mathrm{~s})$ & - \\
\hline 14 & $56,9(d)$ & $1,03(1 \mathrm{H}, \mathrm{m})$ & $56,8(d)$ & $1,00(1 \mathrm{H}, \mathrm{m})$ \\
\hline \multirow[t]{2}{*}{15} & $24,5(\mathrm{t})$ & $1,07(1 \mathrm{H}, \mathrm{m})$ & $24,4(t)$ & $1,06(1 \mathrm{H}, \mathrm{m})$ \\
\hline & & $1,56(1 \mathrm{H}, \mathrm{m})$ & & $1,55(1 \mathrm{H}, \mathrm{m})$ \\
\hline \multirow[t]{2}{*}{16} & $28,4(\mathrm{t})$ & $1,26(1 \mathrm{H}, \mathrm{m})$ & $28,9(\mathrm{t})$ & $1,27(1 \mathrm{H}, \mathrm{m})$ \\
\hline & & $1,67(1 \mathrm{H}, \mathrm{m})$ & & $1,71(1 \mathrm{H}, \mathrm{m})$ \\
\hline 17 & $56,1(d)$ & $1,13(1 \mathrm{H}, \mathrm{m})$ & 55,9 (d) & $1,13(1 \mathrm{H}, \mathrm{m})$ \\
\hline 18 & $12,1(q)$ & $0,67(3 \mathrm{H}, \mathrm{s})$ & $12,0(\mathrm{q})$ & $0,70(3 \mathrm{H}, \mathrm{s})$ \\
\hline 19 & $19,5(q)$ & $1,00(3 \mathrm{H}, \mathrm{s})$ & $19,4(q)$ & $1,01(3 \mathrm{H}, \mathrm{s})$ \\
\hline 20 & $40,7(d)$ & $2,02(1 \mathrm{H}, \mathrm{m})$ & 40,5 (d) & $2,04(1 \mathrm{H}, \mathrm{m})$ \\
\hline 21 & $21,2(q)$ & $0,92(3 \mathrm{H}, \mathrm{d}, 6,5)$ & $21,1(q)$ & $1,02(3 \mathrm{H}, \mathrm{d}, 6,8)$ \\
\hline 22 & $138,5(d)$ & $5,16(1 \mathrm{H}, \mathrm{dd}, 8,5 ; 15,0)$ & 138,3 (d) & $5,15(1 \mathrm{H}, \mathrm{dd}, 8,4 ; 15,1)$ \\
\hline 23 & $129,5(d)$ & $5,00(1 \mathrm{H}, \mathrm{dd}, 8,5 ; 15,0)$ & $129,2(d)$ & $5,02(1 \mathrm{H}, \mathrm{dd}, 8,4 ; 15,1)$ \\
\hline 24 & $51,4(d)$ & $1,53(1 \mathrm{H}, \mathrm{m})$ & $51,2(d)$ & $1,53(1 \mathrm{H}, \mathrm{m})$ \\
\hline 25 & $31,8(\mathrm{~d})$ & $1,45(1 \mathrm{H}, \mathrm{m})$ & 31,9 (d) & $1,44(1 \mathrm{H}, \mathrm{m})$ \\
\hline 26 & $21,3(q)$ & $0,84(3 \mathrm{H}, \mathrm{d}, 6,4)$ & $21,2(q)$ & $0,84(3 \mathrm{H}, \mathrm{d}, 6,4)$ \\
\hline 27 & $19,1(q)$ & $0,82(3 \mathrm{H}, \mathrm{d}, 6,1)$ & $19,0(q)$ & $0,83(3 \mathrm{H}, \mathrm{d}, 6,1)$ \\
\hline 28 & $25,6(d)$ & $1,15(1 \mathrm{H}, \mathrm{t}, 3,2)$ & 25,4 (d) & $1,15(1 \mathrm{H}, \mathrm{t}, 3,1)$ \\
\hline 29 & $12,2(q)$ & $0,80(3 \mathrm{H}, \mathrm{t}, 6,0)$ & $12,3(q)$ & $0,80(3 \mathrm{H}, \mathrm{t}, 6,0)$ \\
\hline
\end{tabular}

* Pengukuran ${ }^{1} \mathrm{H}-\mathrm{NMR}$ dilakukan dalam $\mathrm{CDCl}_{3} 400 \mathrm{MHz}$ dan ${ }^{13} \mathrm{C}-\mathrm{NMR}$ pada $\mathrm{CDCl}_{3} 100 \mathrm{MHz}$

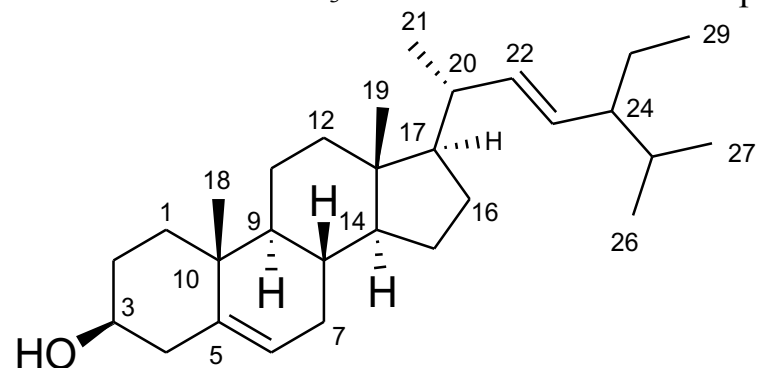

Gambar 4 Struktur kimia senyawa (stigmasterol) 
Berdasarkan hasil interpretasi spektrum IR, ${ }^{1} \mathrm{H}-\mathrm{NMR},{ }^{13} \mathrm{C}-\mathrm{NMR}$ dan data-data pembanding, isolat berupa padatan kristal tak berwarna sebanyak 10,2 mg yang diisolasi dari 2,0 kg serbuk kering kulit batang C. celebicus, ditetapkan sebagai senyawa stigmasterol.

\section{UCAPAN TERIMAKASIH}

Terimakasih kami sampaikan Prof. Dr. M. Hanafi beserta staf pada Pusat Penelitian Kimia Lembaga Ilmu Pengetahuan Indonesia (LIPI) Serpong yang telah mebantu pengukuran NMR.

\section{DAFTAR PUSTAKA}

Awang, K., Chong, L., Marthi, M.T., Mokhtar, R.M., Chan, G., Litaudon, M., Gueritte, F. \& Mohamad, K. 2012. Malayanines $\mathrm{A}$ and $\mathrm{B}$, two novel limonoids from Chisocheton erythrocarpus Hiern, Tetrahedron Letters, 53(40), 5355-5359.

Cayme, J., \& Ragasa, C. 2004. Structure elucidation of $\beta$-stigmasterol and $\beta$ sitosterol from Sesbania grandiflaora (Linn). Pers. and $\beta$-carotene from Heliotropium indicum Linn by NMR spectroscopy. Journal of Kimika. 20(1/2), 5-12.

Inada, A., Sukemawa, M., Murata, H., Nakanishi, T., Tokuda, H., Nishino, H., Iwashima, Darnaedi, D. \& Murata, J. 1993. Phytochemical studies on Maleaceous Plant. Part VII. Structures and Inhibitory Effects on Epstein-Barr Virus Activation of Triterpenoida from leaves of Chisocheton macrophyllus King. Chemical and Pharmaceutical Bulletin. 41(3), 617-619.

Lim, C.S. 2008. Chemical Constituents of Chisocheton erythrocarpus hiern.
Department of Chemistry Faculty of Science University Malaya.

Mohamad, K., Hirasawa, Y., Lim, C.S., Awang, K., Hamid, A., Hadi, A., Takeya, K. \& Morita, H. 2008. Ceramicines A and walsogyne A, novel limonoids from two species of Meliaceae. Tetrahedron Letters, 49(27), 4276-4278.

Najmuldeen, I.A., Ibrahim, A., Tasyriq, M., Lionel, L.A.I., Mohamad, K., Awang, K. \& Hasima, N. 2012. 7 $\alpha$-hidroxy- $\beta$ sitosterol from Chisocheton tomentosus Induces Apoptosis via Dysregulation of Cellular Bax/Bcl-2 Ratio and Cell Cycle Arrest by Downregulating ERK1/2 Activation. Evidence-Based Complementary and Alternative Medicine. 2012, 1-12

Vossen, V.D., H.A.M. \& Umali, B.E. 2002. Plant Resources Of South-East Asia: Vegetable Oils And Fats, Prosea Foundation: Bogor.

Wong, C.P., Shimada, M., Nagakura, Y., Nugroho, A.E., Hirasawa, Y., Kaneda, T., Awang, K., Hamid, A., Hadi, A., Mohamad, K., Shio, M. \& Morita, H. 2011. Ceramicines E-I, New Limonoids from Chisocheton ceramicus. Chemical and Pharmaceutical Bulletin. 59(3), 407-411.

Wong, C.P., Kaneda, T., Hamid, A., Hadi, A. \& Morita, H. 2013. Ceramicine B. a limonoid with anti-lipid droplets accumulation activity from Chisocheton ceramicus. Journal of Natural Medicines. 68(1), 22-30.

Yang, M.H., Wang, J.S., Luo, J.G., Wang, X.B. \& Kong, L.Y. 2009. Tetranortriterpenoids from Chisocheton Paniculatus. Journal of Natural Product. 72(11), 2014-2018

Yayli, N. \& Baltaci, C. 1996. The sterols of Cyclamen coum. Turkish Journal of Chemistry. 20(4), 329-334. 